\title{
Scleroderma Renal Crisis Complicated with Thrombotic Microangiopathy Triggered by Influenza B Virus Infection
}

\author{
Toshimasa Shimizu ${ }^{1}$, Naoki Iwamoto ${ }^{1}$, Momoko Okamoto ${ }^{1}$, Yushiro Endo ${ }^{1}$, Sosuke Tsuji ${ }^{1}$, \\ Ayuko Takatani ${ }^{1}$, Takashi Igawa ${ }^{1}$, Masataka Umeda ${ }^{1}$, Shoichi Fukui ${ }^{1}$, Remi Sumiyoshi ${ }^{1}$, \\ Mineaki Kitamura ${ }^{2}$, Tomohiro Koga ${ }^{1}$, Shin-ya Kawashiri ${ }^{1}$, Kunihiro Ichinose ${ }^{1}$, Mami Tamai ${ }^{1}$, \\ Hideki Nakamura ${ }^{1}$, Tomoki Origuchi ${ }^{1,3}$, Tomoya Nishino ${ }^{2}$ and Atsushi Kawakami ${ }^{1}$
}

\begin{abstract}
:
A 44-year-old Japanese man with a 14-year history of limited cutaneous systemic sclerosis (SSc) was admitted with a fever, hypertension, anemia, thrombocytopenia, and renal dysfunction. On admission, hypertension, hyperreninemia, acute renal dysfunction, hemolytic anemia, and thrombocytopenia led to the diagnosis of scleroderma renal crisis (SRC) complicated with thrombotic microangiopathy (TMA). The patient had also been infected with influenza B virus almost six days before admission. Following treatment with plasma exchange, an angiotensin-converting enzyme inhibitor, and an anti-virus agent, his general condition improved. He had no risk factors for SRC. In SSc patients, an influenza virus infection might trigger SRC complicated with TMA.
\end{abstract}

Key words: scleroderma renal crisis, TMA, SSc, influenza virus

(Intern Med 58: 441-445, 2019)

(DOI: 10.2169/internalmedicine.1441-18)

\section{Introduction}

Systemic scleroderma (SSc) is a connective tissue disease characterized by progressive fibrosis of the skin and internal organs (1). Scleroderma renal crisis (SRC) is the main renal manifestation of SSc, characterized by malignant hypertension, rapidly progressive renal failure, and high mortality (2). Thrombotic microangiopathy (TMA) is characterized by organ dysfunction due to platelet thrombi in the microvasculature, microangiopathic hemolytic anemia, and destructive thrombocytopenia and is occasionally complicated with SRC (3). Generally, SRC occurs in the early phase of SSc (within 4 years), and several risk factors for SRC, including the diffuse cutaneous type and positivity of antiRNA-polymerase III antibody, have been identified; however, the triggers for SRC remain unclear.

We herein report a limited cutaneous SSc patient with
SRC complicated with TMA during the long-term clinical course triggered by an influenza B virus infection.

\section{Case Report}

A 44-year-old Japanese man presented to his primary care physician with a fever, coryzal symptoms, polyarthralgia, and general malaise for 2 days in February 2016. He had hypertension (blood pressure, 236/140 $\mathrm{mmHg}$ ), thrombocytopenia (platelets, $3.8 \times 10^{4} / \mu \mathrm{L}$ ), anemia (hemoglobin $9.3 \mathrm{~g} /$ $\mathrm{dL}$ ), and renal dysfunction [estimated glomerular filtration rate (eGFR), $\left.34.8 \mathrm{~mL} / \mathrm{min} / 1.73 \mathrm{~m}^{2}\right]$, and irbesartan/amlodipine was initiated.

He was transferred to our hospital with thrombocytopenia and anemia, and developed renal damage four days later. At 30 years of age, he was diagnosed with limited cutaneous SSc based on Raynaud's phenomenon, sclerotic skin, skin ulcers on the hands and legs, positivity for anti-

\footnotetext{
${ }^{1}$ Department of Immunology and Rheumatology, Nagasaki University Graduate School of Biomedical Sciences, Japan, ${ }^{2}$ Department of Nephrology, Nagasaki University Graduate School of Biomedical Sciences, Japan and ${ }^{3}$ Department of Rehabilitation Sciences, Nagasaki University Graduate School of Biomedical Sciences, Japan

Received: April 23, 2018; Accepted: June 25, 2018; Advance Publication by J-STAGE: August 24, 2018

Correspondence to Dr. Naoki Iwamoto, naoki-iwa@nagasaki-u.ac.jp
} 
Table 1. Laboratory Findings on Admission.

\begin{tabular}{|c|c|c|c|}
\hline Hematology & & Immunological test & \\
\hline WBC & $4.510^{3} / \mu \mathrm{L}$ & Anti-nuclear antibody & $2,560 \times($ speckled $)$ \\
\hline $\mathrm{RBC}$ & $2.4410^{6} / \mu \mathrm{L}$ & Anti-RNP antibody & 206.1 \\
\hline $\mathrm{Hb}$ & $7.5 \mathrm{~g} / \mathrm{dL}$ & Anti-SM antibody & $(-)$ \\
\hline $\mathrm{Ht}$ & $22.7 \%$ & Anti-Scl-70 antibody & $(-)$ \\
\hline PLT & $5.410^{4} / \mu \mathrm{L}$ & Anti-centromere antibody & $(-)$ \\
\hline Reticulocyte & $2.45 \%$ & anti-RNA-polymerase III antibody & $(-)$ \\
\hline Schistocytes on blood smear & $(+)$ & Anti-double stranded-DNA antibody & $(-)$ \\
\hline Coagulation & & Anti-cardiolipin antibody & $(-)$ \\
\hline PT-INR & 1.01 & Lupus anticoagulant & $(-)$ \\
\hline APTT & $36.9 \mathrm{sec}$ & MPO-ANCA & $<1.0 \mathrm{U} / \mathrm{mL}$ \\
\hline Fibrinogen & $422 \mathrm{mg} / \mathrm{dL}$ & PR3-ANCA & $16.6 \mathrm{U} / \mathrm{mL}$ \\
\hline FDP & $5.0 \mu \mathrm{g} / \mathrm{mL}$ & Anti-GBM antibody & $(-)$ \\
\hline vWF antigen & $361 \%$ & Direct Coombs test & $(-)$ \\
\hline Biochemistry & & Indirect Coombs test & $(-)$ \\
\hline $\mathrm{TP}$ & $6.0 \mathrm{~g} / \mathrm{dL}$ & ADAMTS13 activity & $60.3 \%$ \\
\hline Alb & $2.8 \mathrm{~g} / \mathrm{dL}$ & ADAMTS13 inhibitor & $<0.5 \%$ \\
\hline T-Bil & $0.8 \mathrm{mg} / \mathrm{dL}$ & Thrombomodulin (reference range: $2.1-4.1$ ) & $6.5 \mathrm{FU} / \mathrm{mL}$ \\
\hline AST & $32 \mathrm{IU} / \mathrm{L}$ & Plasma & \\
\hline ALT & $21 \mathrm{IU} / \mathrm{L}$ & Plasma renin activity (reference range: $0.2-2.7$ ) & $10.0 \mathrm{ng} / \mathrm{mL} / \mathrm{hr}$ \\
\hline LDH & $527 \mathrm{IU} / \mathrm{L}$ & Infection & \\
\hline ALP & $247 \mathrm{IU} / \mathrm{L}$ & Nasopharyngeal swab & Influenza B (+) \\
\hline$\gamma$-GTP & $46 \mathrm{IU} / \mathrm{L}$ & Anti-HBs antigen & $(-)$ \\
\hline $\mathrm{CK}$ & $87 \mathrm{IU} / \mathrm{L}$ & Anti-HBs antibody & $(-)$ \\
\hline UA & $6.5 \mathrm{mg} / \mathrm{dL}$ & Anti-HCV antibody & $(-)$ \\
\hline BUN & $39 \mathrm{mg} / \mathrm{dL}$ & Urinalysis & \\
\hline Cre & $2.91 \mathrm{mg} / \mathrm{dL}$ & Protein & $(2+)$ \\
\hline eGFR & $20.35 \mathrm{~mL} / \mathrm{min} / 1.73 \mathrm{~m}^{2}$ & Occult blood & $(2+)$ \\
\hline $\mathrm{Na}$ & $133 \mathrm{mEq} / \mathrm{L}$ & Sediment & \\
\hline $\mathrm{K}$ & $3.2 \mathrm{mEq} / \mathrm{L}$ & $\mathrm{RBC} / \mathrm{HPF}$ & 1-2 cells/HPF \\
\hline $\mathrm{Cl}$ & $101 \mathrm{mEq} / \mathrm{L}$ & WBC/HPF & $<1$ cells/HPF \\
\hline CRP & $1.85 \mathrm{mg} / \mathrm{dL}$ & Granular cast & 3-4 cast/WF \\
\hline Ferritin & $494 \mu \mathrm{g} / \mathrm{dL}$ & UPCR & $3.3 \mathrm{~g} / \mathrm{gCr}$ \\
\hline Haptoglobin & $<5.0 \mathrm{mg} / \mathrm{dL}$ & & \\
\hline \multicolumn{4}{|c|}{$\begin{array}{l}\gamma \text {-GTP: } \gamma \text {-glutamyltransferase, ADAMTS13: a disintegrin and metalloprotease with thrombospondin type-1 repeats: member 13, Alb: albumin, ALP: al- } \\
\text { kaline phosphatase, ALT: alanine transaminase, APTT: activated partial thromboplastin time, AST: aspartate transaminase, BUN: blood urea nitrogen, } \\
\text { Ca: calcium, CK: creatinine kinase, Cl: chlorine, Cre: creatinine, CRP: C-reactive protein, eGFR: estimate glomerular filtration rate, FDP: fibrin/fibrino- } \\
\text { gen degradation product, GBM: glomerular basement membrane, Hb: hemoglobin, HBc: hepatitis B core, HBs: hepatitis B surface, HCV: hepatitis C vi- } \\
\text { rus, Ht: hematocrit, K: potassium, LDH: lactate dehydrogenase, MPO-ANCA: myeloperoxidase anti-neutrophil cytoplasmic antibody, Na: sodium, PLT: } \\
\text { platelets, PR3-ANCA: proteinase-3 anti-neutrophil cytoplasmic antibody, PT-INR: international normalized ratio of prothrombin time, RBC: red blood } \\
\text { cells, T-bil: total bilirubin, TIBC: total iron-binding capacity, TP: total protein, UA: uric acid, UPCR: urine protein to creatinine ratio, vWF: von Wille- } \\
\text { brand factor, WBC: white blood cells }\end{array}$} \\
\hline
\end{tabular}

ribonucleoprotein (RNP) antibody, and reflux esophagitis according to LeRoy's classification (4). He had never developed any other organ involvement. He had hypertension and a smoking history of 20 cigarettes per day, although his renal function was normal (eGFR: around $100 \mathrm{~mL} / \mathrm{min} / 1.73$ $\mathrm{m}^{2}$ ). We administered oral prednisolone, oral tacrolimus, antiplatelet agent, and a vasodilator for refractory skin ulcers and losartan for hypertension. His sclerotic skin slowly progressed, and his blood pressure was well controlled; however, he defaulted on his treatment in July 2015.

On admission, his vital signs were as follows: body temperature, $39.0^{\circ} \mathrm{C}$; pulse rate, $81 / \mathrm{min}$; blood pressure, $130 / 80$ $\mathrm{mmHg}$; and oxygen saturation, $99 \%$ on room air, and his consciousness was clear. A physical examination revealed sclerotic skin of both hands with a modified Rodnan skin score at 6/51 and skin ulcer scars on both lower legs. His lung and heart sounds were normal. The results of the laboratory tests on admission are shown in Table 1.

The patient's anemia had progressed, and hemolytic anemia was confirmed by the presence of schistocytes on a blood smear, elevated lactate dehydrogenase (LDH), and decreased haptoglobin. Direct and indirect Coombs tests were negative. His plasma renin activity was elevated. We therefore diagnosed him with SRC complicated with TMA based on the patient's acute hypertension, hyperreninemia, progressive renal dysfunction with proteinuria, hemolytic anemia, and thrombocytopenia. We later noticed that the patient's disintegrin and metalloprotease with thrombospondin type-1 


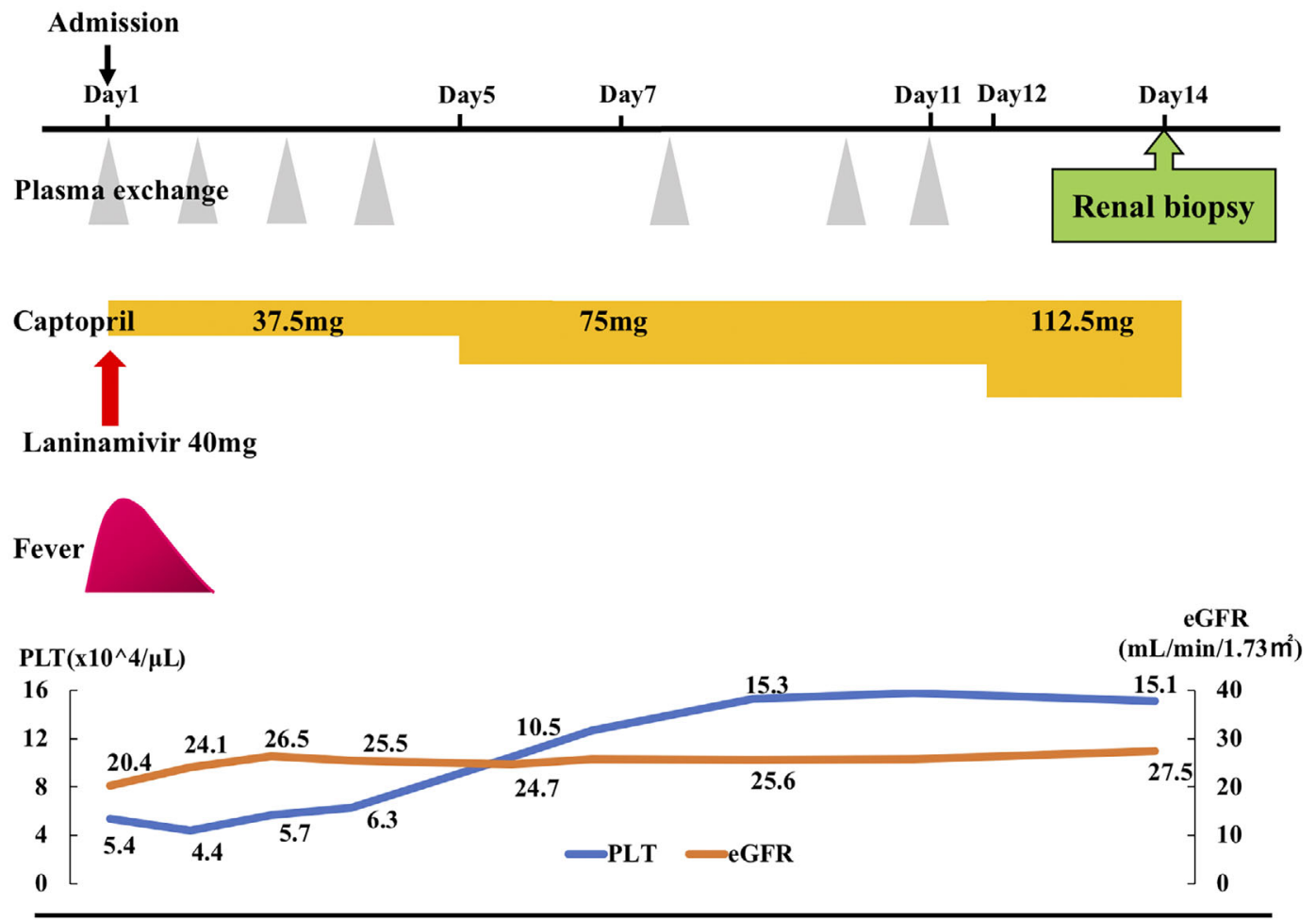

Figure 1. The clinical course after admission. eGFR: estimate glomerular filtration rate, PLT: platelets

repeats, member 13 (ADAMTS13) activity was mildly decreased, and ADAMTS13 inhibitor was not detected. Echocardiography demonstrated neither cardiac insufficiency nor pulmonary artery hypertension. Chest radiograph and thoracoabdominal computed tomography demonstrated no abnormal findings. The patient's influenza B virus infection was revealed by an influenza B virus rapid antigen test during screening for the origin of his fever. Although the proteinase-3 anti-neutrophil cytoplasmic antibody (PR3ANCA) level was elevated, the patient had no findings of vasculitis such as purpura, peripheral neuropathy, or lung involvement, with the exception of renal dysfunction.

Plasma exchange (PE) treatment for the patient's TMA was performed 7 times over 11 days, and we replaced the irbesartan/amlodipine for SRC with captopril, in addition to the initiation of laninamivir for the influenza virus infection. The patient did not resume immunosuppressive agent treatment because of the absence of immunological activity. Although his renal dysfunction persisted, his general condition, anemia, and thrombocytopenia improved after he started treatment (Fig. 1).

Because the patient's PR3-ANCA level was elevated, we performed a kidney biopsy to exclude the possibility of glomerulonephritis on hospital day 14. The kidney biopsy findings are shown in Fig. 2. Some interlobular arteries revealed thrombi deposition and intimal thickening with the proliferation of intimal cells (so-called onion-skin lesion). No findings of glomerulonephritis were observed. These findings were consistent with SRC and TMA (Fig. 2).

\section{Discussion}

We encountered a limited cutaneous SSc patient with SRC complicated with TMA who had no risk factors for SRC during the long-term clinical course and was triggered by an influenza $\mathrm{B}$ virus infection.

SRC is a life-threating condition characterized by malignant hypertension and rapidly progressive renal failure during the course of SSc, and the prognosis is poor (2). It was reported that SRC develops in $4.2 \%$ of patients with diffuse cutaneous SSc and in only $1.1 \%$ of patients with limited cutaneous SSc (5). The pathogenesis of SRC is due to vascular endothelial damage affecting interlobular and arcuate arteries of the kidneys with intimal proliferation leading to decreased renal perfusion and juxtaglomerular apparatus hyperplasia and renin secretion, which results in acute hypertension and acute renal dysfunction.

Several risk factors for developing SRC have been identified, including a duration of SSc $<4$ years, diffuse cutaneous $\mathrm{SSc}$, rapid progression of skin thickening, new anemia, new cardiac event, anti-RNA-polymerase III antibodies, exposure to corticosteroids (prednisolone $>15 \mathrm{mg} /$ day within the previous 3 months), and exposure to cyclosporine within the previous 3 months (6). Interestingly, the present patient had no risk factors for SRC.

TMA is a pathological condition characterized by microangiopathic hemolytic anemia, destructive thrombocytopenia, and organ damage due to platelet thrombi. Thrombotic thrombocytopenic purpura (TTP) is the typical pheno- 


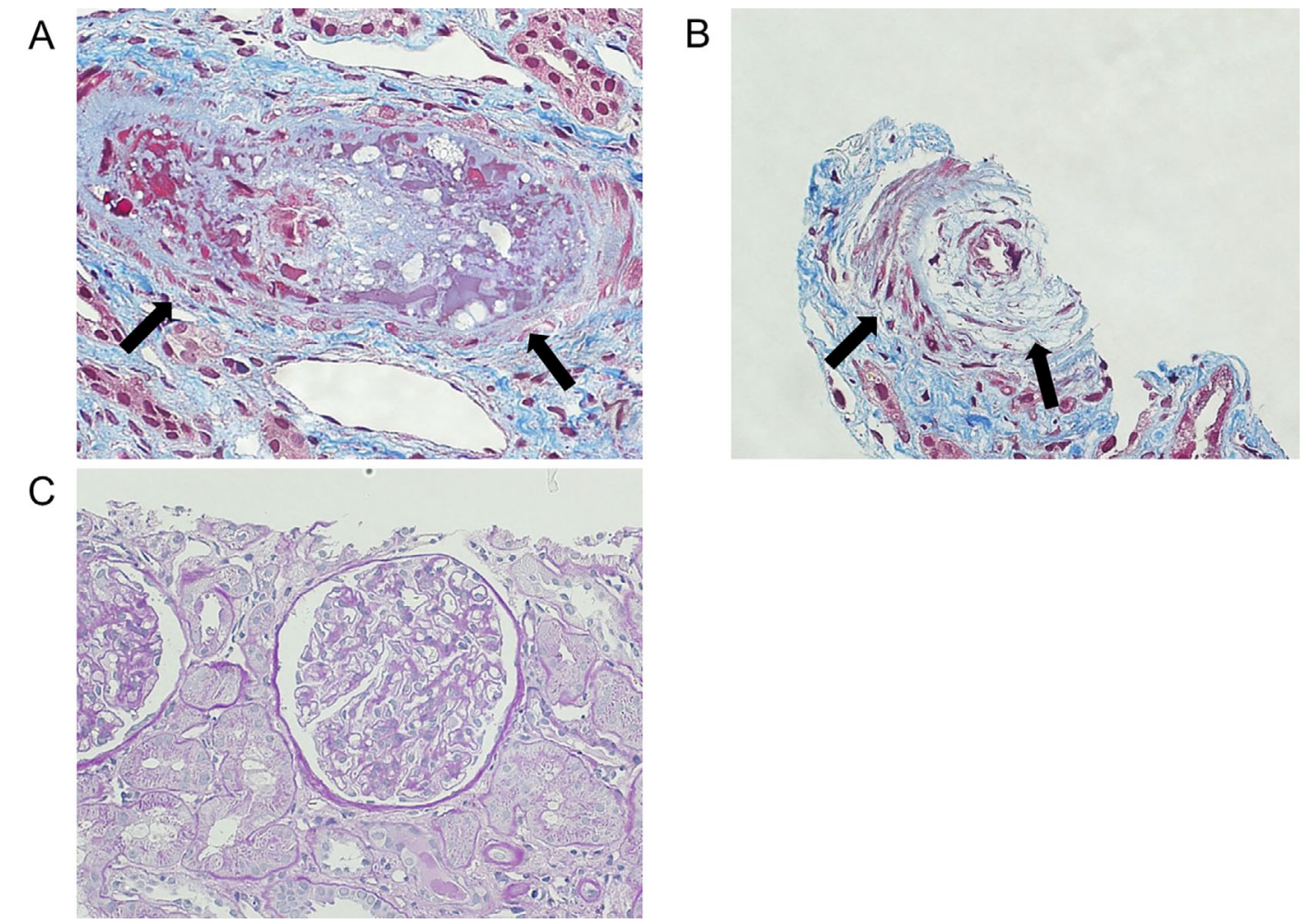

Figure 2. Kidney biopsy findings. A: A thrombus in the interlobular arteries (arrow). Masson trichrome staining $\times 400$. B: Onion-skin lesion (arrow). Masson trichrome staining $\times 400$. C: Glomerulonephritis findings were not observed. PAS staining $\times 200$.

Table 2. TMA Induced by Influenza Virus Infection.

\begin{tabular}{|c|c|c|c|c|c|c|c|}
\hline $\begin{array}{l}\text { Age (years) } \\
\text { sex }\end{array}$ & $\begin{array}{c}\text { Underlying } \\
\text { disease }\end{array}$ & $\begin{array}{c}\text { Type of } \\
\text { influenza virus }\end{array}$ & $\begin{array}{l}\text { ADAMTS13 } \\
\text { activity }\end{array}$ & $\begin{array}{l}\text { ADAMTS13 } \\
\text { inhibitor }\end{array}$ & Treatment & Outcome & References \\
\hline $35 \mathrm{~F}$ & None & A & low & positive & PE Corticosteroid & Improvement & (10) \\
\hline $68 \mathrm{~F}$ & None & A & $<0.5 \%$ & positive & PE Corticosteroid & Death & (11) \\
\hline $27 \mathrm{M}$ & None & $\mathrm{A}(\mathrm{H} 1 \mathrm{~N} 1)$ & N/A & N/A & PE Corticosteroid & Improvement & (12) \\
\hline 12 unknown & None & A (H1N1) & N/A & N/A & PE & Improvement & (14) \\
\hline $18 \mathrm{~F}$ & Atypical HUS & $\mathrm{A}(\mathrm{H} 1 \mathrm{~N} 1)$ & $37 \%$ & negative & PE & Improvement & (14) \\
\hline $11 \mathrm{M}$ & $\begin{array}{c}\text { Hereditary } \\
\text { heterozygous } \\
\text { PS deficiency }\end{array}$ & $\mathrm{A}(\mathrm{H} 1 \mathrm{~N} 1)$ & $68 \%$ & negative & PE Corticosteroid & Improvement & (15) \\
\hline $44 \mathrm{M}$ & $\mathrm{SSc}$ & B & $60.3 \%$ & negative & PE ACEi & Improvement & Present Case \\
\hline
\end{tabular}

ACEi: angiotensin-converting enzyme inhibitor, ADAMTS13: a disintegrin and metalloprotease with thrombospondin type-1 repeats: member 13, HUS: hemolytic uremic syndrom, N/A: not assessed, PE: plasma exchange, SSc: systemic sclerosis, TMA: thrombotic microangiopathy

type of TMA associated with severe deficiency of ADAMTS13 activity caused by the presence of ADAMTS13 inhibitor. In this condition, unusually large von Willebrand factor multimers (UL-VWFMs) produced by vascular endothelial cells are left uncleaved in the circulation, resulting in the production of platelet thrombi (3). However, in the present patient, the deficiency of ADAMTS13 activity was mild, and ADAMTS13 inhibitor was not detected. The mechanism underlying TMA without a severe deficiency of ADAMTS13 activity is thought to involve the impairment of the vascular endothelial function, similar to the suspected mechanism of SRC, resulting in an increase in UL-VWFMs beyond the amount that can be efficiently cleaved by ADAMTS13 (7). In fact, it has been reported that approxi- mately half of SRC cases are complicated by TMA $(2,8)$. In the present patient, the elevated plasma levels of VWF antigen and thrombomodulin were consistent with findings of vascular endothelial damage. In addition, the pathological findings in the kidney revealed onion-skin lesion, indicating latent vascular endothelial damage occurring over the long term.

Our patient was thought to be infected with influenza B virus before admission because of his prolonged fever. It has been suggested that TMA may be able to be induced by several factors, including viral infections (9), such as influenza. Table 2 summarizes the case reports of TMA triggered by influenza virus infections (10-15).

Among the reported cases, although two patients had 
ADAMTS13 inhibitor and showed a severe deficiency of ADAMTS13 activity, another two patients as well as our own had only a mild deficiency of ADAMTS13 activity without the inhibitor, suggesting that vascular endothelial damage due to influenza virus infection induced TMA. We therefore speculate that the exacerbation of vascular endothelial damage due to the influenza virus infection triggered the SRC complicated with TMA in our patient.

To manage SRC, treatment with an angiotensin-converting enzyme inhibitor (ACEi), especially captopril, should be started, and the patient's blood pressure should be controlled as quickly as possible $(16,17)$. The mortality of SRC is not affected by complication with TMA (18). However, it was shown that SRC patients complicated with TMA who were treated with PE in addition to an ACEi had a higher survival rate and a lower rate of developing end-stage renal disease than those treated with an ACEi only (19). Our patient was successfully treated with PE in addition to an ACEi.

In conclusion, we herein described a limited cutaneous SSc patient with SRC complicated with thrombotic microangiopathy triggered by an influenza $B$ virus infection. It should be noted that a common disease, such as influenza virus infection, can induce severe conditions such as SRC and thrombotic microangiopathy through vascular endothelial damage, even when no risk factors are present.

The authors state that they have no Conflict of Interest (COI).

\section{References}

1. Gabrielli A, Avvedimento EV, Krieg T. Scleroderma. N Engl J Med 360: 1989-2003, 2009.

2. Mouthon L, Berezne A, Bussone G, Noel LH, Villiger PM, Guillevin L. Scleroderma renal crisis: a rare but severe complication of systemic sclerosis. Clin Rev Allergy Immunol 40: 84-91, 2011.

3. George JN, Nester CM. Syndromes of thrombotic microangiopathy. N Engl J Med 371: 654-666, 2014.

4. LeRoy EC, Black C, Fleischmajer R, et al. Scleroderma (systemic sclerosis): classification, subsets and pathogenesis. J Rheumatol 15: 202-205, 1988.

5. Walker UA, Tyndall A, Czirjak L, et al. Clinical risk assessment of organ manifestations in systemic sclerosis: a report from the EULAR Scleroderma Trials And Research group database. Ann Rheum Dis 66: 754-763, 2007.

6. Bussone G, Berezne A, Pestre V, Guillevin L, Mouthon L. The scleroderma kidney: Progress in risk factors, therapy, and prevention. Curr Rheumatol Rep 13: 37-43, 2011.
7. Matsuyama T, Kuwana M, Matsumoto M, Isonishi A, Inokuma S, Fujimura Y. Heterogeneous pathogenic processes of thrombotic microangiopathies in patients with connective tissue diseases. Thromb Haemost 102: 371-378, 2009.

8. Guillevin L, Berezne A, Seror R, et al. Scleroderma renal crisis: a retrospective multicentre study on 91 patients and 427 controls. Rheumatology (Oxford) 51: 460-467, 2012.

9. Barbour T, Johnson S, Cohney S, Hughes P. Thrombotic microangiopathy and associated renal disorders. Nephrol Dial Transplant 27: 2673-2685, 2012.

10. Jonsson MK, Hammenfors D, Oppegaard O, Bruserud O, Kittang AO. A 35-year-old woman with influenza A-associated thrombotic thrombocytopenic purpura. Blood Coagul Fibrinolysis 26: 469472, 2015.

11. Kosugi N, Tsurutani Y, Isonishi A, Hori Y, Matsumoto M, Fujimura Y. Influenza A infection triggers thrombotic thrombocytopenic purpura by producing the anti-ADAMTS13 IgG inhibitor. Intern Med 49: 689-693, 2010.

12. Koh YR, Hwang SH, Chang CL, Lee EY, Son HC, Kim HH. Thrombotic thrombocytopenic purpura triggered by influenza A virus subtype H1N1 infection. Transfus Apher Sci 46: 25-28, 2012.

13. Mammas IN, Koutsaftiki C, Papantzimas K, et al. Thrombocytic thrombocytopenic purpura in a child with A/H1N1 influenza infection. J Clin Virol 51: 146-147, 2011.

14. Akiyama R, Komori I, Hiramoto R, Isonishi A, Matsumoto M, Fujimura Y. H1N1 influenza (swine flu)-associated thrombotic microangiopathy with a markedly high plasma ratio of von Willebrand factor to ADAMTS13. Intern Med 50: 643-647, 2011.

15. Tsujii $\mathrm{N}$, Nogami $\mathrm{K}$, Yoshizawa $\mathrm{H}$, et al. Influenza-associated thrombotic microangiopathy with unbalanced von Willebrand factor and a disintegrin and metalloproteinase with a thrombospondin type 1 motif, member 13 levels in a heterozygous protein Sdeficient boy. Pediatr Int 58: 926-929, 2016.

16. Kowal-Bielecka O, Fransen J, Avouac J, et al. Update of EULAR recommendations for the treatment of systemic sclerosis. Ann Rheum Dis 76: 1327-1339, 2017.

17. Walker KM, Pope J; participating members of the Scleroderma Clinical Trials C, Canadian Scleroderma Research G. Treatment of systemic sclerosis complications: What to use when first-line treatment fails-a consensus of systemic sclerosis experts. Semin Arthritis Rheum 42: 42-55, 2012.

18. Teixeira L, Mouthon L, Mahr A, et al. Mortality and risk factors of scleroderma renal crisis: a French retrospective study of 50 patients. Ann Rheum Dis 67: 110-116, 2008.

19. Cozzi F, Marson P, Cardarelli S, et al. Prognosis of scleroderma renal crisis: a long-term observational study. Nephrol Dial Transplant 27: 4398-4403, 2012.

The Internal Medicine is an Open Access journal distributed under the Creative Commons Attribution-NonCommercial-NoDerivatives 4.0 International License. To view the details of this license, please visit (https://creativecommons.org/licenses/ by-nc-nd/4.0/).

(C) 2019 The Japanese Society of Internal Medicine Intern Med 58: 441-445, 2019 